\title{
Análise da composição e distribuição da arborização de ruas como ferramenta para o planejamento urbano
}

\author{
Analysis of the composition and distribution of street trees as a tool for urban planning \\ Análisis de la composición y distribución del arbolado viario como herramienta para la planificación
}

urbana

Recebido: 21/01/2022 | Revisado: 29/01/2022 | Aceito: 09/02/2022 | Publicado: 13/02/2022

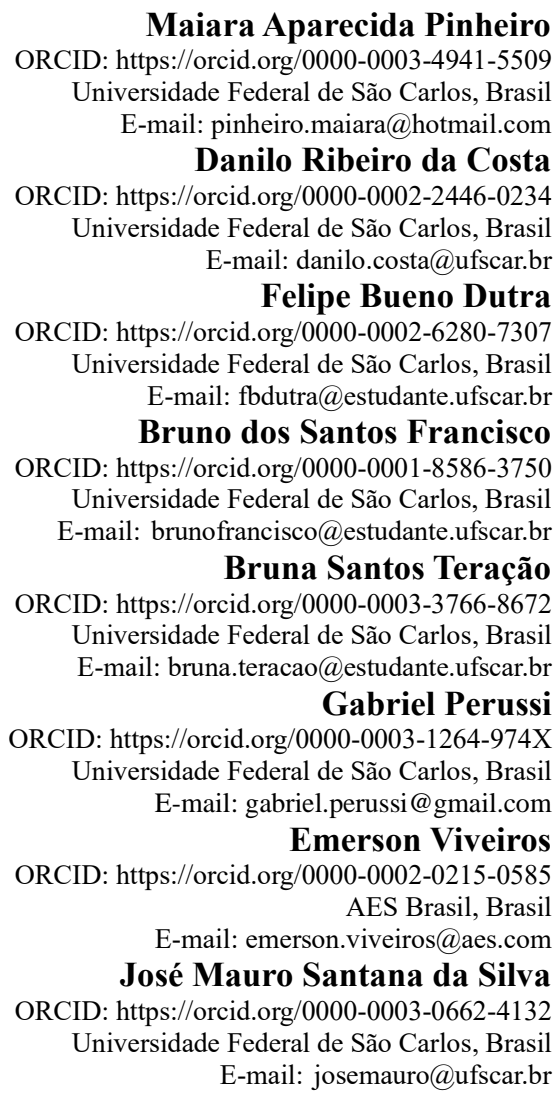

\begin{abstract}
Resumo
O planejamento urbano de um município, quando bem realizado, resulta em aumento da qualidade de vida dos munícipes via diversos fatores, como melhor mobilidade urbana, conforto térmico e até benefícios na saúde. Diante do aumento da urbanização e seu impacto no meio ambiente, bem como a necessidade da criação de políticas públicas, o objetivo do trabalho foi avaliar a situação do planejamento urbano do bairro Jardim Aeroporto do município de Itu, São Paulo, Brasil. Foi realizado o inventário e georreferenciamento dos indivíduos arbóreos de 22 vias. Para análise da distribuição espacial, os dados foram avaliados utilizando-se o índice de Kernel e o índice de grau de atenção. Foram amostrados 338 indivíduos arbóreos distribuídos em 26 famílias e 47 espécies, sendo a espécie Murraya paniculata (L.) Jack, de origem exótica a mais frequente $(15,68 \%)$. Apenas uma via apresentou nível de atenção baixo, as demais ficaram entre médio e alto nível de atenção $(\mathrm{n}=21)$. Além disso constatou-se um déficit de 1352 árvores no bairro. Os resultados mostram que as vias do bairro Jardim Aeroporto têm distribuição desigual de indivíduos arbóreos com uma quantidade considerável de espécies exóticas utilizadas na arborização regional. A proximidade entre algumas árvores e sua distribuição em áreas de risco na cidade mostram como muitas vezes não há um planejamento urbano de longo prazo, podendo causar riscos à integridade física de imóveis e munícipes quando associados ao manejo inadequado das espécies.
\end{abstract}

Palavras-chave: Crescimento urbano; Gestão de áreas verdes; Qualidade de vida; SIG; Geotecnologias. 


\begin{abstract}
The urban planning of a municipality, when well carried out, results in an increase in the quality of life of citizens via several factors, such as better urban mobility, thermal comfort and even health benefits. Faced with the increase in urbanization and its impact on the environment, as well as the need to create public policies, the objective of this work was to evaluate the situation of urban planning in the Jardim Aeroporto neighborhood of the municipality of Itu, São Paulo, Brazil. An inventory and georeferencing of the tree individuals of 22 routes was carried out. To analyze the spatial distribution, the data were evaluated using the Kernel index and the degree of attention index. A total of 338 arboreal individuals distributed in 26 families and 47 species were sampled, with the most frequent species Murraya paniculata (L.) Jack, of exotic origin (15.68\%). Only one route had a low level of attention, the others were between medium and high level of attention $(n=21)$. In addition, there was a deficit of 1352 trees in the neighborhood. The results show that the roads of the Jardim Aeroporto neighborhood have an uneven distribution of arboreal individuals with a considerable amount of exotic species used in regional afforestation. The proximity between some trees and their distribution in risk areas in the city show how often there is no long-term urban planning, which can cause risks to the physical integrity of properties and citizens when associated with inadequate management of the species.
\end{abstract}

Keywords: S Urban growth; Management of green areas; Quality of life; GIS; Geotechnologies.

\title{
Resumen
}

La planificación urbanística de un municipio, cuando está bien realizada, se traduce en un aumento de la calidad de vida de los ciudadanos a través de varios factores, como una mejor movilidad urbana, confort térmico e incluso beneficios para la salud. Ante el aumento de la urbanización y su impacto en el medio ambiente, así como la necesidad de crear políticas públicas, el objetivo de este trabajo fue evaluar la situación de la planificación urbana en el barrio Jardim Aeroporto del municipio de Itu, São Paulo, Brasil. Se realizó un inventario y georreferenciación de los individuos arbóreos de 22 rutas. Para analizar la distribución espacial, los datos se evaluaron mediante el índice de Kernel y el índice de grado de atención. Se muestrearon un total de 338 individuos arbóreos distribuidos en 26 familias y 47 especies, siendo la especie más frecuente Murraya paniculata (L.) Jack, de origen exótico (15,68\%). Solo una ruta tuvo un nivel de atención bajo, las demás estuvieron entre un nivel de atención medio y alto $(\mathrm{n}=21)$. Además, hubo un déficit de 1352 árboles en el barrio. Los resultados muestran que los caminos del barrio Jardim Aeroporto tienen una distribución desigual de individuos arbóreos con una cantidad considerable de especies exóticas utilizadas en la forestación regional. La proximidad entre algunos árboles y su distribución en zonas de riesgo de la ciudad muestran que muchas veces no existe una planificación urbana de largo plazo, lo que puede ocasionar riesgos a la integridad física de las propiedades y de los ciudadanos cuando se asocia a un manejo inadecuado de la especie.

Palabras clave: Crecimiento urbano; Gestión de áreas verdes; Calidad de vida; SIG; Geotecnologías.

\section{Introdução}

O aumento do processo de urbanização mundial apresenta diversos desafios, principalmente pela falta de planejamento urbano adequado em países em desenvolvimento (Santos et al., 2001). O Brasil não é uma exceção, pois mais de $80 \%$ de sua população vive na zona urbana (Angeoletto et al., 2016), o que gera demanda por habitação, saneamento básico, mobilidade e serviços de saúde. Além do mais, o crescimento urbano e populacional gera grandes impactos no meio ambiente, como a poluição e degradação ambiental, resultando em perdas de qualidade dos recursos naturais (Mesquita et al., 2017).

Entre os impactos ambientais gerados, a retirada da vegetação urbana ou a sua exclusão no planejamento das cidades é um ponto crucial a ser considerado, pois a presença de árvores no meio urbano pode atuar na regulação da temperatura, captura de dióxido de carbono, aumento da qualidade do ar, promoção da biodiversidade e ainda proporcionar melhora na saúde humana (Alvey, 2006; Pires et al., 2010; Souza et al., 2013; Silva et al., 2021; Osako et al., 2022). Arborização urbana inclui o plantio da vegetação ao longo de ruas urbanas e parques urbanos, bosques, locais abandonados e áreas residenciais (Alvey, 2006). Segundo Crispim et al. (2018) grande parte das espécies arbóreas devem fazer parte da arborização de vias públicas, ou seja, aquelas plantadas linearmente nas calçadas e canteiros centrais ao longo de ruas e avenidas.

O plantio de árvores em espaços urbanos deve ser inserido nas políticas públicas e sua implantação deve ser feita de forma adequada, o que significa trazer os benefícios oriundos da vegetação e diminuir os problemas de conflitos urbanos que possam existir (Andrade et al., 2015; Jardim et al., 2020). Para construir um planejamento urbano correto que leve em consideração a arborização urbana é necessário um levantamento dos locais a serem arborizados, como também daqueles que necessitam ser complementados ou adaptados (Landgraf et al., 2013). Além disso, incluir o uso de ferramentas de 
geoprocessamento é indispensável na elaboração do plano, pois, possui grande potencial de aplicação na descrição de dados espaciais a partir da realidade, além de permitir a correlação de objetos urbanos com a localização e agrupamento de informações sobre cada objeto (Lima Neto et al., 2012). Uma dessas ferramentas é chamada de índice de Kernel que utiliza a densidade dos dados vetoriais pelo uso de interpolação vetorial. Para esse índice, quanto maior a densidade de pontos em uma determinada área, maior é a superfície gerada. Isso gera um mapa com diferentes intensidades de densidade de pontos em um determinado local (Longley et al., 2005).

Diante do aumento da urbanização e a demanda pela criação de políticas públicas que garantem a qualidade de vida da população, conciliada com a conservação do meio ambiente, o uso de instrumentos de geoprocessamento que podem ser um importante aliado no suporte para o planejamento e manejo da arborização urbana. Assim, o objetivo desse estudo consistiu em quantificar a arborização urbana no bairro Jardim Aeroporto, no município de Itu, estado de São Paulo e analisar a distribuição espacial da arborização do bairro como importante dado para o planejamento urbano e ambiental.

\section{Material e Métodos}

\section{Área de estudo}

O estudo foi conduzido no bairro Jardim Aeroporto no Município de Itu, SP (Figura 1), localizado a aproximadamente 100 km da cidade de São Paulo. A cidade de Itu tem uma densidade demográfica de 177.150 habitantes e compreende uma área de $640,719 \mathrm{~km}^{2}$ de extensão territorial. O clima apresenta classificação "Cfa" segundo Köeppen e variação média anual de temperatura de $21,4{ }^{\circ} \mathrm{C}$ com uma pluviosidade média de $1.285 \mathrm{~mm} /$ ano (Köeppen, 1948). Apresenta diferentes categorias florestais nativas, sendo uma transição entre dois biomas (Cerrado e Mata Atlântica), tendo como principais formações florestais presentes as Florestas Ombrófilas Densa e Floresta Estacional Semidecidual (Instituto Florestal, 2020).

Figura 1. Mapa da Arborização Urbana do bairro Jardim Aeroporto e sua localização em Itu, SP.
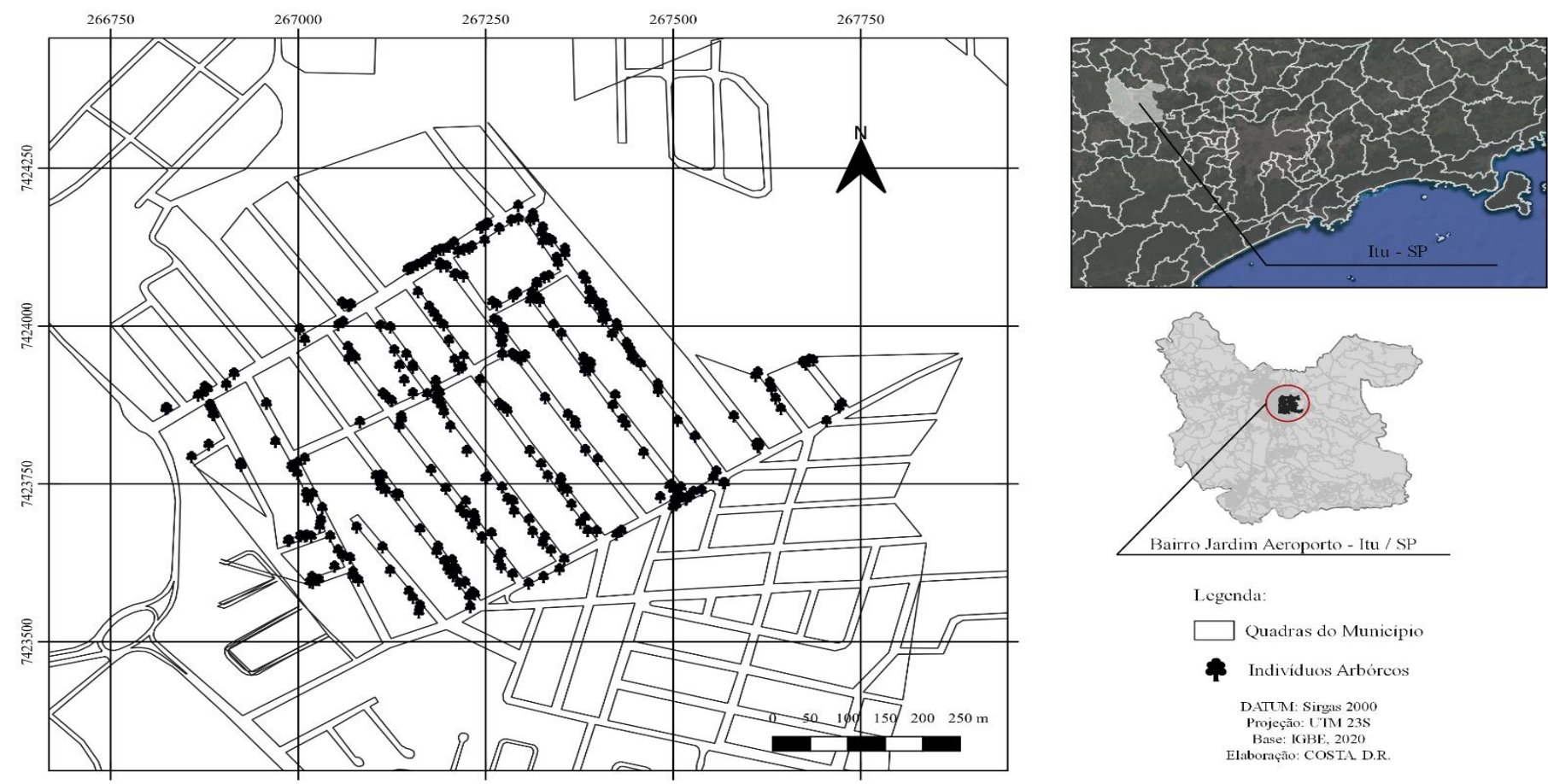

Fonte: Autores (2022).

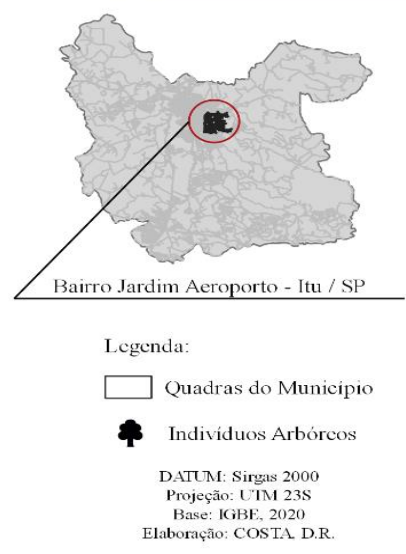




\section{Coleta e análise de dados}

Para o levantamento florístico e fitossociológico foram inventariadas 22 vias do bairro Jardim Aeroporto. As espécies foram classificadas em nível de família, gênero e espécie e calculadas as frequências absoluta e relativa. As espécies foram identificadas em campo e, quando necessário, identificadas a posteriori com auxílio de estereomicroscópio e bibliografia pertinente (Carvalho, 2003; 2006; 2008; 2010; 2014). A base de classificação dos táxons foi a Flora do Brasil (2020). Os indivíduos foram georreferenciados pelo auxílio de um receptor GPS de navegação. Foi contabilizado o número dos indivíduos arbóreos por via e a extensão da via. Todos os cálculos foram realizados em ambiente SIG pela utilização do Software QGIS na versão 3.16, programa de domínio público e uso livre. Visando compreender a quantidade de árvores por quilômetro da via, realizou-se a mensuração do índice do grau de atenção em relação a ações operacionais como manejo e manutenção dos indivíduos arbóreos, pois, classifica as vias segundo um determinado grau de importância conforme Tabela 1 (Iwama, 2014 ; Tadenuma et al., 2021).

Tabela 1. Indicador do grau de importância em relação ao nível de atenção das árvores nas vias.

\begin{tabular}{|c|c|}
\hline Árvores/km & Nível de atenção \\
\hline$>100$ & Baixo \\
\hline 60 a 100 & Médio \\
\hline 40 a 60 & Alto \\
\hline 10 a 40 & Muito Alto \\
\hline$<10$ & Extremamente Alto \\
\hline
\end{tabular}

Fonte: Tadenuma et al., (2021).

A partir do operador de índice de Kernel (Equação 1) (Camargo et al., 2004), foi estimada a densidade de árvores na via bem como a forma em que os indivíduos arbóreos estavam espacialmente distribuídos ao longo da extensão da mesma.

$$
k(x, y, z)=\frac{3}{\pi \tau^{2}} \cdot\left(1-\frac{d_{i j}^{2}}{2 \tau^{2}}\right)^{2} k(x, y, z)=\frac{3}{\pi \tau^{2}} \cdot\left(1-\frac{d_{i j}^{2}}{2 \tau^{2}}\right)^{2}
$$

O índice de Kernel demonstra a influência da vizinhança em relação ao valor dos pontos a partir de um raio de busca $(\tau)$ e uma relação de distância euclidiana $\left(d_{i j}^{2} d_{i j}^{2}\right)$, normalmente o raio de busca deve ser interpretado para o tipo de fenômeno a ser visualizado. Quando a análise visa fenômenos deve-se utilizar valores maiores. Porém, ao observar questões mais locais deve-se utilizar valores menores de raios (Camargo et al., 2004). Na análise foi utilizado um raio de 20 metros no entorno dos pontos a fim de averiguar a presença ou não de componentes arbóreos próximos uns dos outros.

\section{Resultados e Discussão}

Foram inventariados 338 indivíduos arbóreos distribuídos em 26 famílias e 47 espécies (Tabela 2), sendo Fabaceae a mais representativa (12 espécies), seguida de Bignoniaceae (6 espécies) e Myrtaceae (4 espécies) (Figura 2). Apesar da maioria das espécies amostradas serem nativas do Brasil (51\%), a mais frequente foi Murraya paniculata (L.) Jack (15,68\%), considerada exótica (Flora do Brasil, 2020). Isso se deve ao uso histórico de espécies vegetais exóticas no paisagismo urbano como praças e 
ruas, tornando-se uma prática promotora da redução da diversidade das espécies nativas (Bechara et al., 2016) no ambiente urbano.

Segundo Melo et al., (2008) deve-se diversificar a escolha de espécies nativas, prezando pelo plantio daquelas que desempenham papéis ecológicos e sociais, de conforto térmico, alimento para a fauna e outros, possibilitando que a população humana desfrute de um ambiente integrado à paisagem nativa. Além disso, é importante destacar a preferência por espécies arbóreas compatíveis com o local de plantio (Emer et al., 2013).

As espécies mais frequentes na amostragem foram Murraya paniculata, Cenostigma pluviosum (DC.) Gagnon \& G.P.Lewis (10,35\%), Delonix regia (Bojer ex Hook.) Raf. (6,31\%), Moquilea tomentosa Benth. (5,62\%), Ligustrum lucidum W.T.Aiton (4,14\%) (exótica) e Bauhinia forficata Link (3,85\%), que, juntas, correspondem a 45,85\% da arborização do bairro. Os 54,15\% restantes da arborização estão constituídos pelas demais espécies, indicando uma distribuição irregular (Tabela 2).

Segundo Silva (2000) é comum que poucas espécies representem a maior parte da arborização, como o ocorrido no município. Outros autores obtiveram o mesmo resultado, entre eles nos inventários dos municípios de Aracaju (Santos et al., 2015), Vitória do Xingu (Silva et al., 2018) e Monte Alegre (Bacelar et al., 2020).

Tabela 2. Lista de espécies amostradas no bairro Jardim Aeroporto, cidade de Itu, SP. $F_{a}=$ Frequência absoluta; $F_{r}=$ Frequência relativa; $\mathrm{F}_{\mathrm{r}(100 \%)}=$ frequência relativa em porcentagem.

\begin{tabular}{|c|c|c|c|c|c|}
\hline Nome da espécie & Família & Origem & $\mathbf{F a}$ & $\mathbf{F}_{\mathbf{r}}$ & $\mathbf{F}_{\mathbf{r}(100 \%)}$ \\
\hline Murraya paniculata (L.) Jack & Rutaceae & Exótica & 53 & 0,157 & 15,7 \\
\hline $\begin{array}{l}\text { Cenostigma pluviosum (DC.) Gagnon \& } \\
\text { G.P.Lewis }\end{array}$ & Fabaceae & Nativa & 35 & 0,104 & 10,4 \\
\hline Delonix regia (Bojer ex Hook.) Raf. & Fabaceae & Exótica & 21 & 0,062 & 6,2 \\
\hline Moquilea tomentosa Benth. & Chrysobalanaceae & Nativa & 19 & 0,056 & 5,6 \\
\hline Ligustrum lucidum W.T.Aiton & Oleaceae & Exótica & 14 & 0,041 & 4,1 \\
\hline Bauhinia forficata Link & Fabaceae & Nativa & 13 & 0,038 & 3,8 \\
\hline Terminalia catappa $\mathrm{L}$. & Combretaceae & Naturalizada & 12 & 0,036 & 3,6 \\
\hline $\begin{array}{l}\text { Centrolobium tomentosum Guillem. ex } \\
\text { Benth. }\end{array}$ & Fabaceae & Nativa & 11 & 0,033 & 3,3 \\
\hline Ficus sp. & Moraceae & Nativa & 11 & 0,033 & 3,3 \\
\hline Leucaena leucocephala (Lam.) de Wit & Fabaceae & Exótica & 11 & 0,033 & 3,3 \\
\hline Malpighia glabra L. & Malpighiaceae & Exótica & 11 & 0,033 & 3,3 \\
\hline Salix babylonica $\mathrm{L}$. & Salicaceae & Exótica & 11 & 0,033 & 3,3 \\
\hline Eugenia uniflora L. & Myrtaceae & Nativa & 10 & 0,030 & 3,0 \\
\hline Morus nigra $\mathrm{L}$. & Moraceae & Exótica & 9 & 0,027 & 2,7 \\
\hline Mangifera indica $\mathrm{L}$. & Anacardiaceae & Exótica & 8 & 0,024 & 2,4 \\
\hline Tecoma stans (L.) Juss. ex Kunth & Bignoniaceae & Exótica & 8 & 0,024 & 2,4 \\
\hline Pleroma granulosum (Desr.) D. Don & Melastomataceae & Nativa & 8 & 0,024 & 2,4 \\
\hline Citrus sp. & Rutaceae & Exótica & 7 & 0,021 & 2,1 \\
\hline Magnolia champaca (L.) Baill. ex Pierre & Magnoliaceae & Exótica & 7 & 0,021 & 2,1 \\
\hline Nerium oleander L. & Apocynaceae & Exótica & 6 & 0,018 & 1,8 \\
\hline Handroanthus heptaphyllus (Vell.) Mattos & Bignoniaceae & Nativa & 5 & 0,015 & 1,5 \\
\hline Erythrina falcata & Fabaceae & Nativa & 5 & 0,015 & 1,5 \\
\hline Tabebuia sp. & Bignoniaceae & Nativa & 5 & 0,015 & 1,5 \\
\hline Acacia sp. & Fabaceae & Nativa & 3 & 0,009 & 0,9 \\
\hline Cupressus sempervirens L. & Cupressaceae & Nativa & 3 & 0,009 & 0,9 \\
\hline Apuleia leiocarpa (Vogel) J.F.Macbr. & Fabaceae & Nativa & 2 & 0,006 & 0,6 \\
\hline
\end{tabular}




\begin{tabular}{|c|c|c|c|c|c|}
\hline Nome da espécie & Família & Origem & $\mathbf{F a}$ & $\mathbf{F r}$ & $F_{r(100 \%)}$ \\
\hline Duranta erecta $\mathrm{L}$. & Verbenaceae & NI & 2 & 0,006 & 0,6 \\
\hline Pachira aquatica Aubl. & Malvaceae & Nativa & 2 & 0,006 & 0,6 \\
\hline Persea americana Mill. & Lauraceae & Naturalizada & 2 & 0,006 & 0,6 \\
\hline $\begin{array}{l}\text { Heptapleurum actinophyllum (Endl.) Lowry } \\
\text { \& G.M. Plunkett }\end{array}$ & Araliaceae & Naturalizada & 2 & 0,006 & 0,6 \\
\hline Schinus terebinthifolius Raddi & Anacardiaceae & Nativa & 2 & 0,006 & 0,6 \\
\hline Syagrus romanzoffiana (Cham.) Glassman & Arecaceae & Nativa & 2 & 0,006 & 0,6 \\
\hline Pleroma mutabile (Vell.) Triana & Melastomataceae & Nativa & 2 & 0,006 & 0,6 \\
\hline Baccharis dracunculifolia DC. & Asteraceae & Nativa & 1 & 0,003 & 0,3 \\
\hline Cassia ferruginea (Schrad.) Schrad. ex DC. & Fabaceae & Nativa & 1 & 0,003 & 0,3 \\
\hline Cedrela fissilis Vell. & Meliaceae & Nativa & 1 & 0,003 & 0,3 \\
\hline Ceiba speciosa (A.St.-Hil.) Ravenna & Malvaceae & Nativa & 1 & 0,003 & 0,3 \\
\hline Cojoba arborea (L.) Britton \& Rose & Fabaceae & Nativa & 1 & 0,003 & 0,3 \\
\hline Eriobotrya japonica (Thunb.) Lindl. & Rosaceae & Naturalizada & 1 & 0,003 & 0,3 \\
\hline Eucalyptus globulus Labill. & Myrtaceae & Exótica & 1 & 0,003 & 0,3 \\
\hline Handroanthus albus (Cham.) Mattos & Bignoniaceae & Nativa & 1 & 0,003 & 0,3 \\
\hline Musa acuminata Colla & Musaceae & Exótica & 1 & 0,003 & 0,3 \\
\hline Psidium guajava $\mathrm{L}$. & Myrtaceae & Naturalizada & 1 & 0,003 & 0,3 \\
\hline Punica granatum $\mathrm{L}$. & Lythraceae & Exótica & 1 & 0,003 & 0,3 \\
\hline Spathodea campanulata P. Beauv. & Bignoniaceae & Exótica & 1 & 0,003 & 0,3 \\
\hline Syzygium cumini (L.) Skeels & Myrtaceae & Naturalizada & 1 & 0,003 & 0,3 \\
\hline Tabebuia roseoalba (Ridl.) Sandwith & Bignoniaceae & Nativa & 1 & 0,003 & 0,3 \\
\hline Tipuana tipu (Benth.) Kuntze & Fabaceae & Exótica & 1 & 0,003 & 0,3 \\
\hline Trichilia hirta L. & Meliaceae & Nativa & 1 & 0,003 & 0,3 \\
\hline Total & & & 338 & & \\
\hline
\end{tabular}

Fonte: Autores (2022).

Figura 2. Distribuição do número de espécies por família (forma incluídas famílias com pelo menos duas espécies).

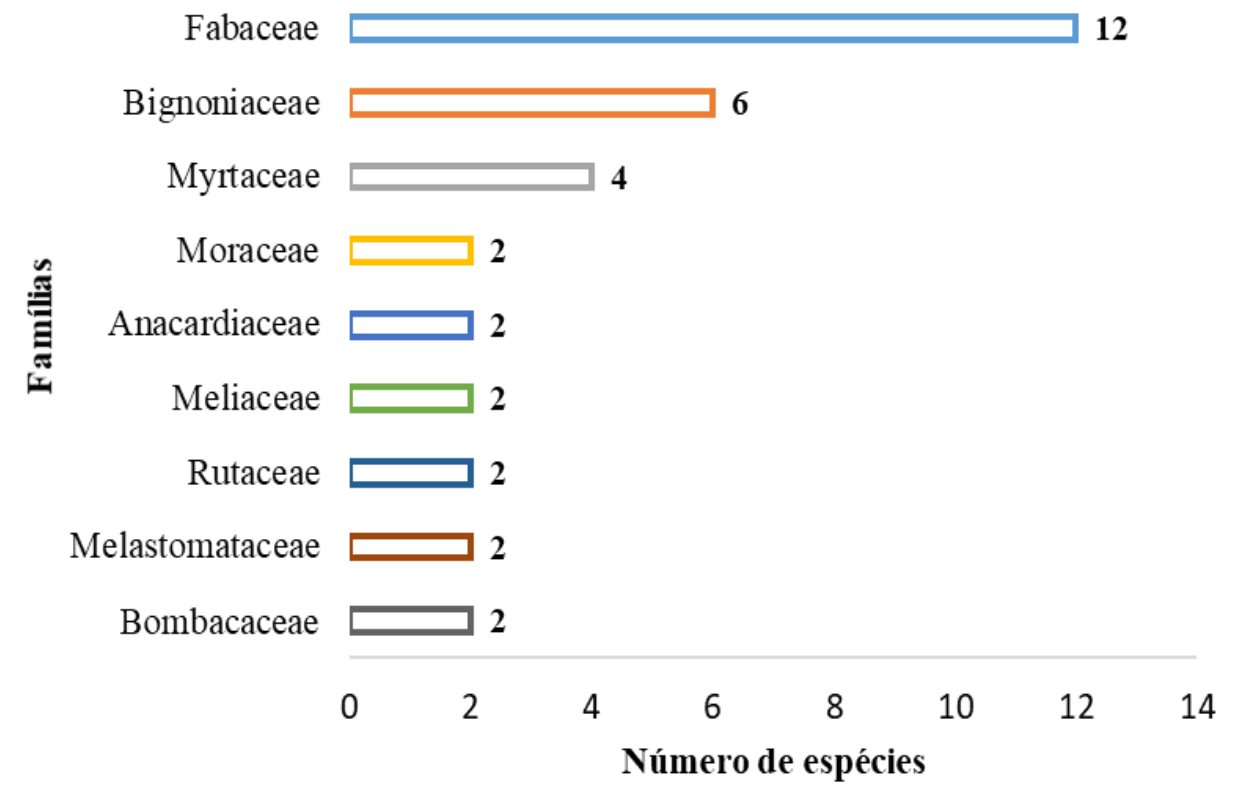

Fonte: Autores (2022). 
Pode-se notar que a maioria das vias $(\mathrm{N}=22)$ apresenta baixo número de árvores por quilômetro de via (Figura 3) e é possível observar que apenas uma rua apresenta baixo nível de atenção, enquanto seis apresentam uma atenção média a questões de manejo e manutenção (Figura 3). O índice de Kernel demonstrou que a distribuição dos indivíduos arbóreos nas vias não segue uma padronização específica em relação ao regramento de ruas, ou seja, existem trechos onde observa-se uma concentração maior de árvores e outros com ausência das mesmas (Figura 4).

Figura 3. Classificação das vias por nível de atenção para a relação árvore/km no bairro Jardim Aeroporto, Itu-SP.

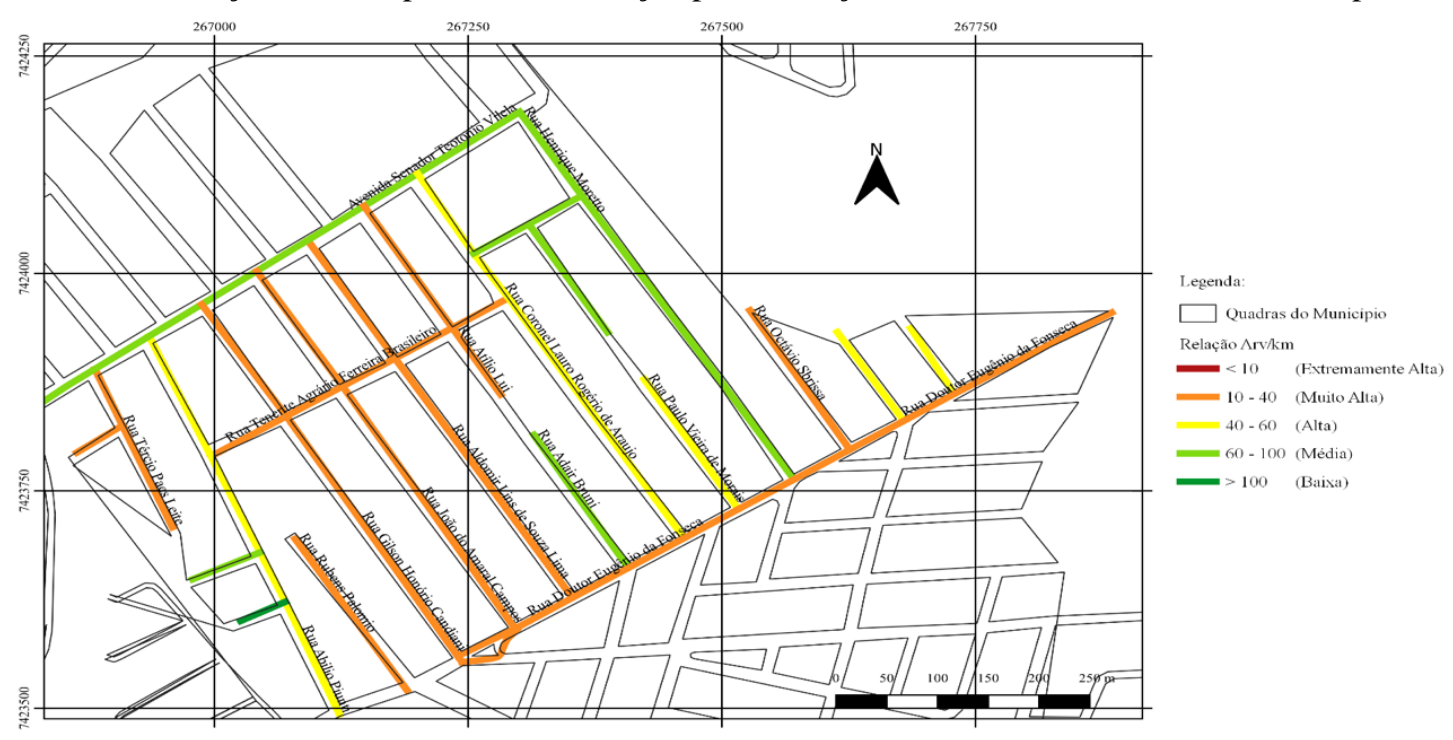

Fonte: Autores.

Figura 4. Índice de Kernel da arborização do bairro Jardim Aeroporto, Itu, SP.

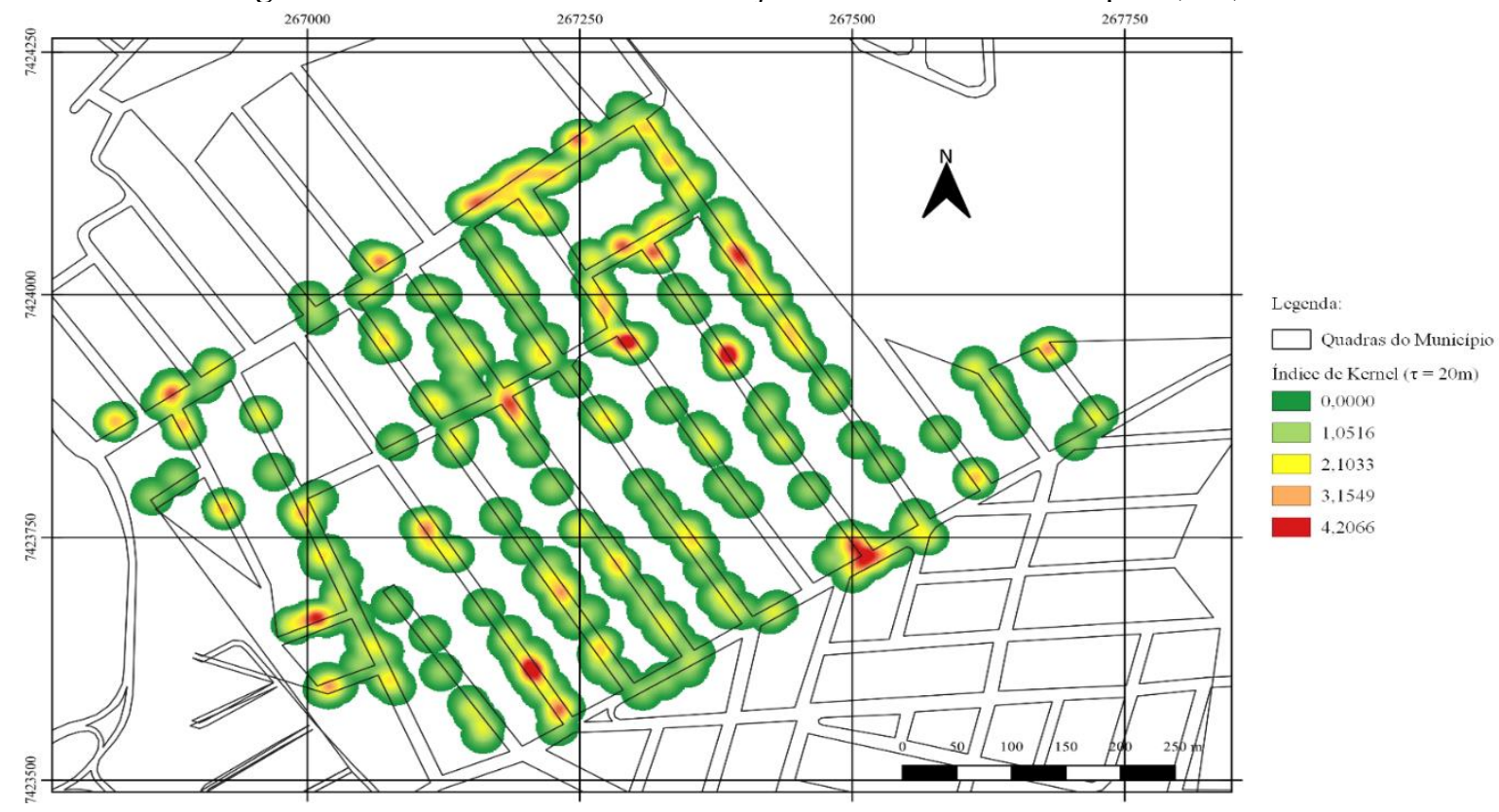

Fonte: Autores.

Considerando o espaçamento de um indivíduo arbóreo a cada seis metros de via em relação ao planejamento das vias existe um déficit de cerca de 1352 árvores. Isso demonstra a baixa importância e planejamento do bairro inerente à arborização 
urbana. Embora alguns logradouros apresentem quantidades próximas ao indicado, em outros não há a presença de exemplares ao longo da sua extensão (Figura 5).

Figura 5. Potencial da implantação de indivíduos arbóreos em relação à situação atual no bairro Jardim Aeroporto, Itu, SP.

$\square$ Potencial de Indivíduos na via $\square \mathrm{N}^{\mathrm{o}}$ de Indivíduos na via

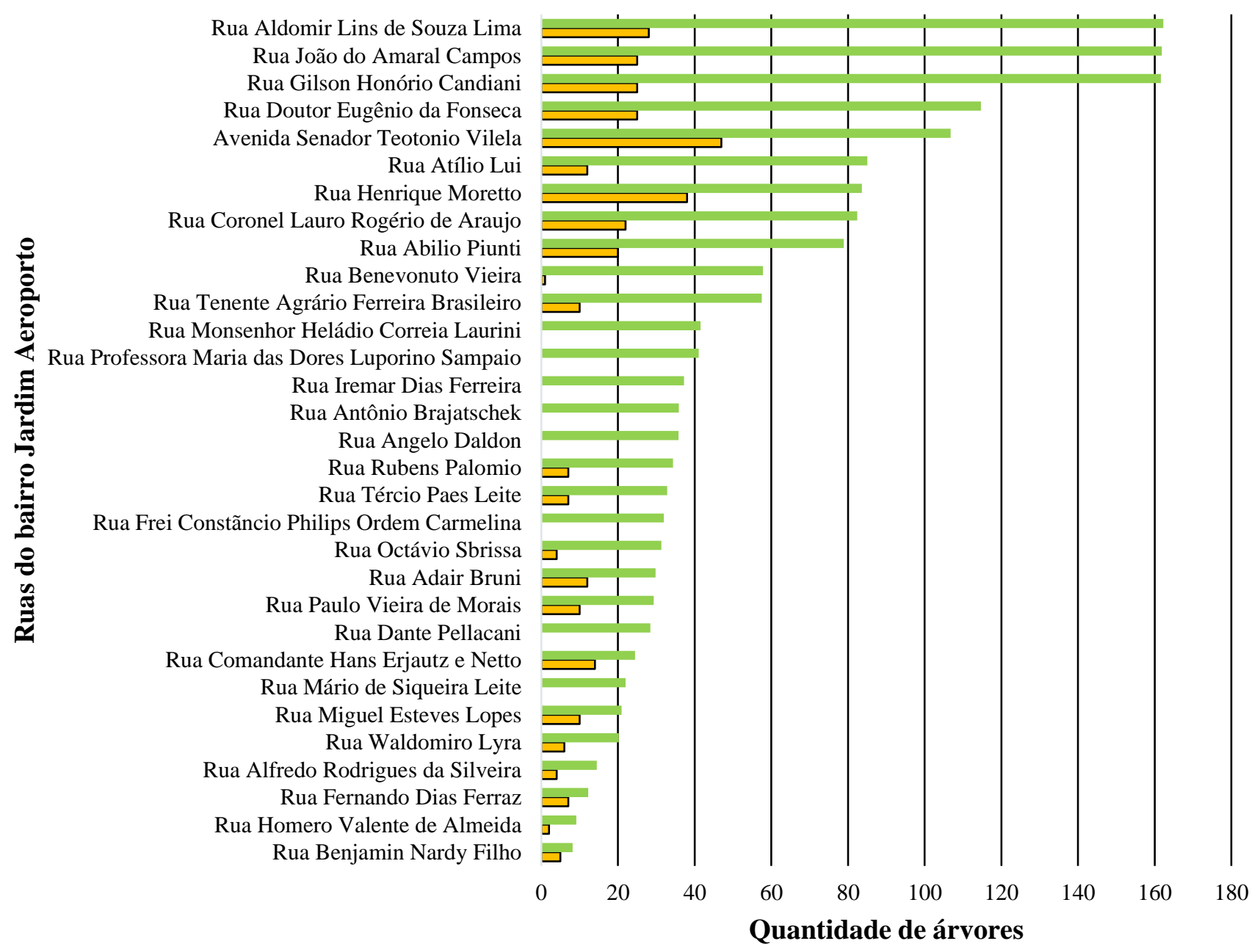

Fonte: Autores (2022).

Esses resultados corroboram que o uso da estatística Kernel pode ser uma ferramenta útil na análise espacial das áreas urbanas e para a avaliação das condições das ruas e pavimentos, dando informações concretas sobre as condições locais do município e permitindo elaboração de estratégias de planejamento urbano que sejam mais efetivas. Tais benefícios já foram discutidos em diferentes estudos há pelo menos uma década, indicando como o uso de ferramentas SIG podem fornecer dados técnicos-científicos de qualidade para atualização de planos diretores urbanos e obtenção de melhores condições de infraestrutura e meio ambiente a médio e longo prazo nas cidades (Alvarez et al., 2009; Falce et al., 2012).Outros estudos mostram resultados semelhantes, com distribuição arbórea desigual entre diferentes locais de uma região resultando em diferentes condições de estrutura viária, fornecimento de serviços ambientais e impacto na qualidade de vida dos munícipes (Mayer et al., 2014; Sartori et al., 2011). 
Durante o levantamento foram identificados alguns empecilhos que são observados na arborização urbana quando realizada incorretamente como: árvores que dificultam a visualização do trânsito e passagem de pedestres; podas irregulares; escolha indevida resultando em problemas com a fiação e pavimentação; descarte incorreto de lixos nas áreas verdes. Para o correto ordenamento das árvores nas vias é necessária a implantação de uma arborização em locais que não prejudiquem o espaço urbano como a proximidade de esquinas, postes, iluminação e placas (Cruz, 2003). Isto é notório no bairro analisado, principalmente pela concentração de árvores em determinados trechos de vias e locais próximos a esquinas como demonstrado pelo Índice de Kernel (Figura 4). Isto em conjunto da maior densidade de indivíduos arbóreos em distâncias menores que cinco metros, podem gerar os diversos problemas apontados, assim como já percebido em outros estudos (Nicodemo et al., 2009).

\section{Conclusões}

A arborização urbana no bairro Jardim Aeroporto, na cidade de Itu, é composta por mais de 50\% de espécies nativas, contudo a espécie mais frequente foi Murraya paniculata, de origem exótica. O bairro mostrou uma distribuição desigual dos indivíduos ao longo do bairro, com alta concentração em alguns trechos de vias, muitas vezes associado a problemas infraestruturais.

Com isso, percebe-se que o desenvolvimento de uma política municipal de arborização urbana que seja efetiva torna-se imprescindível dado às diferentes condições locais encontradas, que podem resultar em maiores impactos urbanos e ambientais no município. Também se reforça a importância da gestão pública municipal utilizar ferramentas geoespaciais que facilitem a obtenção de informações técnicas atualizadas sobre as condições do município, resultando em estratégias mais efetivas e rápidas para o planejamento da arborização urbana.

\section{Referências}

Alvarez, I. A., Oliveira, U. R., de Carvalho, J. C. L. \& Taura, T. A. (2009). Uso de geotecnologias para subsidiar planos de ação da arborização viária do centro de Petrolina-PE. In: Embrapa Semiárido-Artigo em anais de congresso (ALICE). In: congresso brasileiro de arborização urbana, 13, Rio Branco. Diversidade na floresta e na cidade: coletânea de trabalhos. Rio Branco: Sociedade Brasileira de Arborização Urbana.

Alvey, A. A. (2006). Promoting and preserving biodiversity in the urban forest. Urban Forestry \& Urban Greening, 5, $195-201$.

Andrade, M. N. M. M. \& Jeronimo, C. E. M. (2015). Diagnóstico da arborização do espaço urbano da cidade de João Pessoa, PB. Revista Eletrônica em Gestão, Educação e Tecnologia Ambiental, 19 (3), 194-208.

Angeoletto, F., Santos, J. W. M. C., Ruiz Sanz, J. P., Silva, F. F. D. \& Albertín, R. M. (2016). Tipología socio-ambiental de las ciudades medias de Brasil: aportes para un desarrollo urbano sostenible. Urbe. Revista Brasileira de Gestão Urbana, 8, 272-287.

Bacelar, W. J. L., Parry, M. M., Herrera, R. C., França, I. F. D., \& Parry, S. M. (2020). Diagnóstico qualiquantitativo da arborização urbana da cidade de Monte Alegre, Pará, Brasil. Ciência Florestal, 30, 1019-1031.

Bechara, F. C., Topanotti, L. R. \& Silva, L. M. (2015). Aspectos da arborização urbana ecológica. Revista Ibero-Americana de Ciências Ambientais, 7 (1), 49 55 .

Camargo, E. C. G., Fucks, S. D. \& Câmara, G. (2004). Análise espacial de superfícies. In: Druck, S.; Carvalho, M. S.; Câmara, G.; Monteiro

A. M. V. (Ed.). Análise espacial de dados geográficos. Planaltina: Embrapa Cerrados, 79-122.

Carvalho, P. E. R. Espécies arbóreas brasileiras. Brasília, DF. Embrapa Informação Tecnológica; Colombo. Embrapa Florestas, 2003. 1 v. 1039 p. il. (Coleção espécies arbóreas brasileiras, 1).

Carvalho, P. E. R. Espécies arbóreas brasileiras. Brasília, DF. Embrapa Informação Tecnológica; Colombo. Embrapa Florestas, 2006.3 v. 627 p. il.; color. (Coleção espécies arbóreas brasileiras, v. 2).

Carvalho, P. E. R. Espécies arbóreas brasileiras. Brasília, DF. Embrapa Informação Tecnológica; Colombo. Embrapa Florestas, 2008.3 v. 593 p. il.; color. (Coleção espécies arbóreas brasileiras, v. 3).

Carvalho, P. E. R. Espécies arbóreas brasileiras. Brasília, DF. Embrapa Informação Tecnológica; Colombo. Embrapa Florestas, 2010.4 v. 644 p. il.; color. (Coleção espécies arbóreas brasileiras, v. 4).

Carvalho, P. E. R. Espécies arbóreas brasileiras. Brasília, DF. Embrapa Informação Tecnológica; Colombo. Embrapa Florestas, 2014.5 v. 634 p. il.; color. (Coleção espécies arbóreas brasileiras, v. 5). 
Crispim, M. P., Palhano, E. \& Carvalho, S. M. (2018). Tendências de pesquisa em arborização de vias públicas com o uso de geotecnologias. Anais da XXV Semana de Geografia da UEPG. Ponta Grossa (Brasil): Universidade Estadual de Ponta Grossa.

Cruz, B. M. (2003). Procedimentos metodológicos para a avaliação da arborização urbana na cidade de São Paulo. Paisagem e ambiente: ensaios, 31, São Paulo, $25-60$.

Emer, A. A., da Silva, L., Cadorin, D. A. \& Mello, N. A. (2013). Avaliação quantitativa e qualitativa da arborização do bairro Santa Terezinha na cidade de Pato Branco (PR). Ambiência, 9 (1), 129-143.

Falce, B. O., Leão, B. D. A., Souza, D. M. \& Oliveira, F. B. (2012). Análise da distribuição espacial de árvores e arbustos quanto ao porte, à taxonomia e à utilização através de sistema de informação geográfica. Revista da sociedade brasileira de arborização urbana, 7 (1), $23-34$.

Instituto Florestal. (2020). Inventário florestal do Estado de São Paulo: mapeamento da cobertura vegetal nativa. Governo do Estado de São Paulo, Secretaria de Infraestrutura e Meio Ambiente do Estado de São Paulo. https://smastr16.blob.core.windows.net/home/2020/07/inventarioflorestal2020.pdf.

Iwama, A.Y. (2014). Indicador de arborização urbana como apoio ao planejamento de cidades brasileiras. $R E V S B A U, 9$ (3),156-172.

Jardim, J. P. \& Umbelino, G. (2020). Mapeamento de áreas verdes e da arborização urbana: estudo de caso de Diamantina, Minas Gerais. Revista Espinhaço, 9 (2).

Köeppen, W. (1948). Climatologia: con un estudio de los climas de la tierra (No. QC861 K6).

Landgraf, P. R. C., Paiva, P. D. O \& Reis, L. A. (2013). Desenvolvimento de software para o planejamento da arborização urbana. Ornamental Horticulture, 19, 19-24.

Lima Neto, E. M., Biondi, D., Araki, H. \& Bobrowski, R. (2012). Fotografias aéreas para mensuração da área de copa das árvores de ruas de Curitiba-PR. Floresta, 42, 577-586.

Longley, P. Goodchild, M.; Maguire, D. \& Rhind, D. (2005). Geographical Information Systems and Science. 2 ed. Chichester: John Wiley \& Sons Ltd.

Mayer, C. L. D., Oliveira Filho, P. C., \& Bobrowski, R. (2014). Análise espacial de conflitos da arborização de vias públicas: caso Irati, Paraná. Floresta, 45 (1), 11-20.

Melo, E. F. R. Q. \& Romanini, A. (2008). Praça Ernesto Tochetto: Importância da sua preservação histórica e aspectos de sua arborização. Rev. SBAU, 3 (1), 54-72.

Mesquita, F. N., Silvestre, K. S. \& Steinke, V. A. (2017). Urbanização e degradação ambiental: Análise da ocupação irregular em áreas de proteção permanente na região administrativa de Vicente Pires, DF, utilizando imagens aéreas do ano de 2016. Revista Brasileira de Geografia Física,10 (3), $722-734$.

Nicodemo, M.L.F. \& Primavesi, O. (2009). Por que manter árvores na área urbana? Dados eletrônicos. — São Carlos: Embrapa Pecuária Sudeste, 40p.

Osako, L. K., Brito, L., \& Silva, P. A. (2022). Árvores de florestas urbanas: uma ótica ecológica para uma gestão promotora e mantenedora da biodiversidade na cidade. Research, Society and Development, 11(1), e31811124887.

Pires, N. A. M. T., Melo, M. S.; Oliveira, D. E. \& Santos, S. X. (2010). A arborização urbana do município de Goiandira/GO -caracterização quali-quantitativa e propostas de manejo. Revista da Sociedade Brasileira de Arborização Urbana, 5 (3), 185-205.

Santos, C. Z. A. D., Ferreira, R. A., Santos, L. R., Santos, L. I., Gomes, S. H. \& Graça, D. A. S. D. (2015). Análise qualitativa da arborização urbana de 25 vias públicas da cidade de Aracaju-SE. Ciência Florestal, 25, 751-763.

Santos, N. D. \& Teixeira, I. F. (2001). Arborização de vias públicas: ambiente x vegetação. Santa Cruz do Sul: Instituto Souza Cruz, 135p.

Sartori, R. A. \& Balderi, A. P. (2011). Inventário da arborização urbana do município de Socorro-SP e proposta de um índice de danos à infra-infraestrutura das cidades. Revista da Sociedade Brasileira de Arborização Urbana, 6 (4), 68-89.

Silva, A. G. (2000). Arborização urbana em cidades de pequeno porte: avaliação quantitativa e qualitativa. (Dissertação de Mestrado em Ciências Florestais) - Universidade Federal de Viçosa, Viçosa.

Silva, L. A., de Sousa, C. S., Parry, M. M., Herrera, R. C., Oliveira, F. P. M. \& Parry, S. M. (2018). Diagnóstico da arborização urbana da cidade de Vitória do Xingu, Pará, Brasil. Revista da Sociedade Brasileira de Arborização Urbana, 13 (1), 57-72.

Silva, P. A., Silva, L. L., Cherutte, A. G., Gomes, A. C. S., Brito, L., \& Rodrigues, B. M. (2021). Aves visitando flores do ipê-amarelo (Handroanthus vellosoi) na área urbanizada ressalta a importância da interação planta-animal na arborização de cidades. Research, Society and Development, $10(15)$, e414101522982.

Souza, S. M., de Lima Cardoso, A. \& da Silva, A. G. (2013). Estudo da percepção da população sobre a arborização urbana, no município de Alegre-ES. Revista da Sociedade Brasileira de Arborização Urbana, 8 (2), 68-85.

Tadenuma, S. S. K. \& Carvalho, S. M. (2021). Levantamento e potencial de plantio da arborização de calçadas em vias públicas da área urbana de Ponta Grossa, PR. Terr@Plural, 15, 1-16, e2117148.

Toralles C. P. \& Gerundo A. P. de S. (2021). Inventário de arborização viária: Um estudo piloto para o bairro Cassino, na cidade do Rio Grande, RS, Brasil. Projectare Revista de Arquitetura e Urbanismo, 12, 181-198. 